УДК 339.138

DOI: $10.21779 / 2500-1930-2020-35-2-24-33$

\title{
А.М. Магомедов
}

\section{Проблемы развития дистанционной торговли в условиях пандемии}

Дагестанский государственный университет; Россия, 367000, Республика Дагестан, г. Махачкала, ул. М. Гаджиева,43a; ali1955@mail.ru

Пандемия внесла существенные коррективы в структуру и содержание дистанционной торговли. Во время карантина покупатели достаточно быстро адаптировались к онлайншопингу и сформировалась новая устойчивая покупательская привычка - покупка товаров в Интернете. Этот потребительский опыт (customer experience) должен стать в перспективе пятым «Р» маркетингового микса. Стратегические просчеты при продвижении интернетмагазинов приводят к тому, что многие из интернет-магазинов закрываются, не заработав ни одного рубля. В статье предложены стратегии поэтапного продвижения интернет-магазина.

Ключевые слова: дистанциионая торговля, пандемия, онлайн-продажа, интернетмагазин, продвижение сайта, маркетинговые стратегии.

В последние годы в целом в мире и в России отмечены высокие темпы прироста показателей объема интернет-торговли, которые свидетельствуют об изменении потребительских предпочтений в сторону постепенного увеличения покупок в интернетмагазинах и сокращении приобретения товаров в традиционных торговых сетях [5]. По данным аналитической компании Data Insight, в 2019 году объём мирового рынка интернет-торговли составил \$30,6 млрд.

По причине отсутствия в нашей стране стандартных терминов, официальной статистики, касающихся электронной торговли, а также единой системы измерения всех секторов онлайн-торговли, показатели, которые характеризуют ее развитие, базируются только на оценках экспертов и результатах разных исследовательских центров [11].

Таблица 1. Развитие интернет-торговли в России ${ }^{*}$

\begin{tabular}{|l|c|c|c|c|c|}
\hline & 2015 г. & 2016 г. & 2017 г. & 2018 г. & 2019 г. \\
\hline Объем продажи, млн руб. & 710 & 900 & 1070 & 1300 & 1620 \\
\hline Рост объема продажи, \% & 26 & 28 & 19 & 22 & 24 \\
\hline Рост количества заказов, \% & 7 & 21 & 20 & 28 & 41 \\
\hline Рост среднего чека, \% & 18 & 6 & -1 & -5 & -14 \\
\hline
\end{tabular}

* Составлено по данным исследовательской компании Data Insight: http://datainsight.ru/sites/default/files/DI_Ecommerce2019.pdf

Так, по данным Ассоциации компаний интернет-торговли (АКИТ), объем оборота электронной коммерции в России в 2019 году составил 2,03 трлн руб. Покупательскую аудиторию в Интернете АКИТ оценивает в 47,2 млн человек, что на 4,4 млн больше по сравнению с прошлым годом.

Исследовательская компания Data Insight приводит более скромные цифры оборота интернет-торговли - 1,61 трлн руб., чем их коллеги из АКИТ (табл. 1). Но, по разным 
источникам, оборот интернет-торговли растет в последние годы исключительно за счет роста числа заказов (в какой-то части и за счет новых клиентов), при этом наблюдается устойчивое падение среднего размера чека.

Хотя сохраняется высокий тренд развития электронной торговли, нельзя сказать, что она имеет решающее значение в розничном товарообороте страны. Доля онлайнторговли в ВВП нашей страны составляет лишь 1,3 \%, что в два раза меньше, чем в США. В пересчёте же на душу населения рынок электронной коммерции России выглядит еще скромнее и составляет порядка $\$ 170$, что в десять раз меньше, чем в США. Рассчитанный на основе данных вышеприведенных исследовательских центров (Data Insight и АКИТ) оборот электронной коммерции в общем объеме розничного товарооборота страны составляет примерно 4-5 \%. Согласно официальным данным Росстата в 2019 г. доля продаж через Интернет в общем объеме оборота розничной торговли составила только $2 \%$ и за шесть последних лет она выросла лишь на 0,3 \% [6]. Для сравнения, в Германии и Великобритании данный показатель составляет 15-20\%.

Покупатель опасается приобретать товары дистанционно, так как описание товара в действительности может не совпадать с качеством поставленного товара в реальности. В каталоге товар выглядит красиво, без изъянов, а по факту доставляют изделие с тусклыми цветами, неровными швами и дефектами. Конечно, покупатель имеет право вернуть не понравившийся ему товар, но, поскольку потеряно время на его ожидание и нет гарантии, что другой будет лучше, довольствуется тем, что отправили ритейлеры. Правда, в следующий раз он не будет спешить делать онлайн-заказ.

Другая причина слабого развития интернет-торговли, это возможность мошенничества в сети Интернет. Некоторые веб-сайты, получая предоплату за заказываемый товар, вовсе не выполняют свои обязательства. Можно, конечно, привлечь к ответственности ритейлеров, но из-за незначительной суммы заказчики не делают этого, на что и рассчитывают мошенники. Применяемая в данном случае штрафная санкция за невыполнение обязательств должна не только возмещать материальный и моральный ущерб клиенту, но и предотвратить повторение таких действий со стороны недобросовестных участников онлайн-рынка. При стоимости сделки не более одной тысячи руб. следует установить минимальный размер штрафа в сумме 10 тыс. руб., а при стоимости заказа более тысячи руб. установить штраф в десятикратном размере стоимости заказа. Возможно, в этом случае клиенты будут заинтересованы предъявлять иск к недобросовестным ритейлерам, а последние не станут срывать поставки. В итоге у покупателей будет сформировано доверие к онлайн-продажам, что очень важно для их роста.

Дистанционная торговля зависит от цифровизации общества. Многие семьи не имеют возможности приобрести цифровую технику или у них вовсе отсутствует компьютерная грамотность [3]. Большинство исследователей утверждает, что россияне пока не готовы к выполнению программы «Цифровая экономика» $[2,8]$.

Дистанционная торговля (включая и интернет-торговлю) зависит от системы доставки заказов. Логистика сегодня - слабое звено в данном сегменте рынка. Интернетмагазины применяют различные маркетинговые приемы привлечения новых покупателей: начисление баллов или бонусов клиентам, подарки от ритейлеров, возврат денег при срыве сроков поставки и т. д. В ряде случаев это приносит успех.

Коронавирусная пандемия внесла существенные коррективы в структуру и содержание онлайн-торговли. В условиях самоизоляции продолжали работать лишь продуктовые магазины и аптеки. По оценкам аналитиков, три четверти россиян минимизировали свои посещения в магазины или же вовсе перестали их посещать. Продуктовые магазины «у дома» сократили объемы продаж на 20-30 \%, а супермаркеты - на 40-60 \%. 
Для традиционной торговли, в особенности непродовольственной, наступили сложные времена, о чем было заявлено и на федеральном уровне. Не имея выручки, а соответственно доходов, предпринимателям приходится платить арендную плату, зарплату персоналу, проценты за кредит, налоги и нести другие расходы. Невосполнимые убытки несут магазины, реализующие сезонные модные товары: сезон пройдет - модная брендовая вещь станет абсолютно ненужной к следующему сезону. Рухнул туристический бизнес, закрылись предприятия индустрии сервиса и отдыха.

В странах Запада пострадавшие от коронавирусной пандемии предприятия получают существенную помощь от государства, чего не скажешь об отечественном бизнесе. Это говорит о том, что государство не спешит на помощь бизнесу, и, предвидя такое отношение со стороны государства, бизнес не желает выходить из тени. Объем теневой экономики значителен, особенно в регионах. Вот почему отдельные предприятия после 3-4 месяцев простоя возобновили работу без особых усилий, значит, у них имелась финансовая «подушка безопасности».

В первые дни режима самоизоляции с полок магазинов стали сметать товары повседневного спроса (Fast Moving Consumer Goods - FMCG). Цены сегмента FMCG резко выросли, а в домашних хозяйствах их потребительские запасы увеличились - их хватит, возможно, на 3-4 мес. В первые дни самоизоляции муку, крупы, консервы стали закупать впрок. Многие ожидали ввода карточной системы на продукты питания. К удивлению покупателей, продовольственный рынок выдержал этот шок. Талонную систему на товары первой необходимости не ввели, а равновесие на рынке было вскоре восстановлено, и лишь в продаже санитайзеров и отдельных лекарств были сбои. В дальнейшем из этой истории извлекут уроки как продавцы, так и покупатели, а также регулирующие органы.

В то же время пандемия невольно выступила катализатором развития дистанционной торговли по всем направлениям во всех регионах. Благо институт дистанционной торговли был прописан Постановлением Правительства РФ от 27.09.2007 № 612 [9]. Согласно этому нормативному акту для дистанционной торговли характерны следующие признаки:

- продажа товаров по договору розничной купли-продажи, заключаемому на основании ознакомления покупателя с предложенным продавцом описанием товара;

- для описания товара используются каталоги, проспекты, буклеты, фотоснимки, передаваемые продавцом покупателю посредством сетей почтовой связи, электросвязи, включая сети Интернет, а также связи для трансляции теле- и радиоканалов;

- исключается возможность непосредственного ознакомления покупателя с товаром либо образцом товара при заключении договора дистанционной продажи товаров.

Дистанционно в основном можно приобрести продукты питания, лекарства, которые отпускаются без рецепта, одежду, бытовую технику, мебель и прочие товары народного потребления. Не допускается продажа дистанционным способом алкогольной продукции, а также товаров, свободная реализация которых запрещена или ограничена законодательством РФ.

При дистанционном способе продавец обязан предложить покупателю услуги по доставке товара, а плата за такую услугу определяется самим продавцом. Продавец должен также известить потребителя о необходимости привлечения квалифицированных специалистов для введения изделия в эксплуатацию. Закон РФ «О защите прав потребителей» обязывает продавца предоставлять покупателю информацию о потребительских свойствах товара и о праве покупателя возвратить товар продавцу в соответствии с законодательством РФ. 
Пандемия коронавирусной инфекции (COVID-19) и режим самоизоляции придали ускорение развитию интернет-торговли. Так, по прогнозам аналитиков Data Insight, к 2024 году среднегодовой темп роста в данной сфере составит 33,2 \%, что на 6,6 п.П. выше прогнозируемого значения без пандемии. По их же данным, в период самоизоляции в российский онлайн-ритейл пришли не менее 15 млн человек [7]. По оценкам сервиса «Яндекс. Маркет Аналитика», к апрелю 2020 г. аудитория интернет-торговли в России выросла с начала года на 17 млн пользователей - до 63 млн, то есть почти на 40 \%. Однако, как предупреждают эксперты, положительный эффект для рынка станет заметен не сразу, а растянется на несколько лет, так как сначала эта аудитория вернется в торговые центры.

Сами интернет-магазины отмечают рост числа новых клиентов за период пандемии в два-три раза. Так, на Wildberries, который лидирует по обороту среди онлайнритейлеров на российском рынке, за три месяца с середины марта зарегистрировалось около 6 млн новых пользователей (регистрация в сервисе обязательна для покупок), что почти втрое превышает аналогичный показатель прошлого года. Ha Ozon число активных клиентов также почти удвоилось в апреле этого года.

Интернет-магазины стали в два-три раза больше продавать товары первой необходимости, а также средства, укрепляющие иммунитет, санитайзеры и различные витамины.

В условиях пандемии резко изменилась структура дистанционной торговли. Основное место в обороте онлайн-торговли занял сегмент FMCG. На рынок FMCG приходится более половины всех потребительских расходов. Здесь представлены десятки тысяч товарных позиций: продукты питания и напитки; декоративная и гигиеническая косметика; предметы личной гигиены; средства для стирки и уборки; фармацевтические товары; другие товары краткосрочного пользования. Можно выделить следующие особенности продаж FMCG сегмента:

- высокая оборачиваемость товаров, обеспечивающая значительный объем выручки и массу прибыли;

- небольшой жизненный цикл, обуславливающий повседневный спрос и частую покупку товаров кратковременного пользования или с коротким сроком годности, которые потребляются быстро;

- невысокая цена и легкая заменимость;

- $\quad$ высокий объём компенсирует низкую рентабельность отдельных продаж.

В качестве инвестиций акции FMCG обычно дают низкую доходность, но это безопасные ставки с предсказуемой маржой, стабильными регулярными дивидендами.

После завершения периода самоизоляции рынок FMCG интернет-торговли закрепится на новом уровне, поэтому компаниям важно использовать текущую ситуацию, чтобы окончательно сформировать лояльность тех потребителей, которые впервые воспользовались подобными сервисами, и обеспечить себе место на рынке на долгие годы.

В период пандемии доставка продуктов и товаров первой необходимости через сеть Интернет для многих самоизолировавшихся или направленных на принудительный карантин россиян стала единственным средством связи с миром. Произошел резкий наплыв покупателей в онлайн-сервисы доставки продуктов, что привело к сбою в оказании данных услуг.

В новых условиях работы онлайн-сервисы «Перекрёсток» и «Утконос» перестали справляться с кратно выросшим объемом заказов, горизонт доставки увеличился с 1-2 дней до недели и более. В сегменте экспресс-доставки интервалы также увеличились и зачастую превышали заявленные 1-2 часа в несколько раз. Среднее количество размещенных заказов в день на сайте Perekrestok.ru превысило 16 тыс., а средний чек вырос 
почти до 6 тыс. рублей, практически в два раза превысив среднее значение в декабре 2019 года. Количество товаров в одном заказе в марте также увеличилось в 1,5-2 раза с 40 до 60-80 товаров (таких запасов среднестатистической семье хватило бы на 108 дней). Спрос на доставку продуктов рос и в других сервисах: в середине марта количество заказов в «Сбермаркете» и «Утконосе» увеличилось в 2-2,5 раза. На фоне новостей о введении в России нерабочей недели в период с 30 марта по 5 апреля спрос на доставку в «Сбермаркете» вырос на 40 \%, в iGooods - в Москве в 20 раз выше нормы, а в регионах в 10 раз, в «Утконосе» количество заказов выросло на $20 \%$. Как отмечали в исследовательской компании Nielsen, возросли онлайн-продажи супов быстрого приготовления (на $271 \%$ ), туалетной бумаги (на $185 \%$ ), чистящих средств для дома (на $171 \%$ ), соусов (на $136 \%$ ), ультрапастеризованного молока (на $128 \%$ ), воды (на $102 \%$ ), алкоголя и макарон.

Для удовлетворения возросшего спроса в апреле сервисам доставки пришлось запускать новые склады, пересматривать планы по экспансии в регионы и увеличивать число сборщиков и курьеров. Продажей продуктов также стали заниматься и непрофильные компании. Так, фэшн-ритейлер Lamoda на фоне коронавируса запустил продажу продуктов длительного срока хранения.

Потребительский опыт (customer experience) постепенно становится пятым «Р» маркетингового микса. Сегодня сложно переоценить роль положительного СХ в стратегическом развитии дистанционной торговли. Во время карантина покупатели достаточно быстро адаптировались к онлайн-шопингу. В течение нескольких месяцев сформировалась новая устойчивая покупательская привычка - покупка товаров в Интернете. В дальнейшем для удержания своих позиций интернет-магазинам следует придерживаться следующих направлений:

- развитие системы покупательской лояльности, выпуск виртуальных карт, оплата баллами и т. д.;

- внедрение мобильных приложений для покупателей, сотрудников и курьеров;

- $\quad$ расширение зон экспресс-доставки;

- интеграция со службами экспресс-доставки.

Потребительская гибкость, возникшее у людей понимание, что онлайн-покупки способны сэкономить время, стали для многих причиной внедрения и развития нового канала продаж.

По оценкам исследовательского агентства Data Insight, на российском рынке функционирует около 200 тыс. интернет-магазинов с числом оформленных заказов более 10 в сутки [1]. В то же время ежемесячно начинают работу более 1000 площадок электронной торговли и столько же пропадают бесследно [10]. Пандемия однозначно оживила онлайн-бизнес. В апреле этого года число новых открытых интернетмагазинов стало вдвое больше, чем за три предыдущих месяца. Однако число закрывшихся магазинов также возросло в апреле $(39,1 \%)$. Следует правильно выбрать свою нишу, чтобы не закрыться в первый же месяц из-за ошибок в стратегии.

Продвижение интернет-магазина необходимо начать со стандартного чек-листа, по которому работает большинство специалистов по интернет-маркетингу. Он включает в себя следующие пункты:

- техническая оптимизация, работа со структурой и семантикой;

- текстовая оптимизация категорий и подкатегорий;

- оптимизация (путем генерации) карточек товаров;

- покупка и размещение анкорных ссылок;

- контекстная реклама;

- анализ эффективности ключевых слов; 
- повторная покупка анкорных ссылок.

Техническая оптимизация сайта магазина, работа со структурой и сбор максимально широкого семантического ядра осуществляются для последующей текстовой оптимизации посадочных страниц сайта (категорий и подкатегорий). Оптимизация карточек товаров проводится путем генерации их уникальности, для того чтобы они максимально участвовали в ранжировании и соответственно показывали максимально высокую конверсию.

На следующем этапе следует заниматься покупками или размещением анкорных ссылок, чтобы получать первые позиции по ключевым запросам. Подключая контекстную рекламу, можно анализировать эффективность наших ключевых слов или кластеров в семантическом ядре. Если не достигнута цель, продолжаем покупать и размещать ссылки для получения ещё более высоких позиций в поисковых системах.

Собственно стандартная стратегия продвижения интернет-магазина заключается в первую очередь в развитии семантического ядра сайта до максимума (набор слов и словосочетаний, отражающих тематику и структуру сайта): подбор низкочастотных ключевых слов и ключевых слов с длинным хвостом. Анализ конкурентов либо другие техники помогут улучшить текстовый контент, который реально увеличит видимость сайта. Далее продолжаем покупать ссылки и социальные сигналы, забиваем по максимуму ссылочный профиль тематическими и околотематическими ссылками. Затем работа продолжается с коммерческими факторами, которые влияют на конверсию и помогают получить нам больший выхлоп в виде продаж и показать положительный ROI (рентабельность) нашей услуги.

Следует иметь в виду, что интернет-магазины различаются по следующим характеристикам:

- ценовой сегмент;

- длительность и сезонность спроса на товары;

- актуальность и lifetime товара;

- активность целевой аудитории;

- ассортимент магазина.

Ценовой сегмент определяем в следующем порядке:

- выбираем определенную группу товаров, которую собирается иметь наш магазин;

- проводим анализ минимальных и максимальных цен в сравнении с конкурентами

(топ-10), исключая агрегаторов из списка;

- анализ ассортимента (количества предлагаемых товаров);

- определяем сегмент нашего магазина.

В итоге составляем таблицу следующего вида.

Таблица 2. Анализ ценового сегмента интернет-магазина в сравнении с конкурентами

\begin{tabular}{|l|c|c|c|}
\hline & $\begin{array}{c}\text { Ассортимент товаров } \\
\text { (количество) }\end{array}$ & $\begin{array}{c}\text { Минимальная цена } \\
\text { (отклонение } \\
\text { от нашей) }\end{array}$ & $\begin{array}{c}\text { Максимальная цена } \\
\text { (отклонение } \\
\text { от нашей) }\end{array}$ \\
\hline Топ-1 & 342 & $-14,18 \%$ & $-2,22 \%$ \\
\hline Топ-2 & 265 & $-11,62 \%$ & $-1,93 \%$ \\
\hline Топ-3 & 187 & $-12,25 \%$ & $3,50 \%$ \\
\hline$\ldots$ & $\ldots$. & $\ldots$ & $\ldots$ \\
\hline Наш магазин & & 1580 руб. & 3450 руб. \\
\hline
\end{tabular}


В результате анализа ценового сегмента можно провести следующую классификацию сегментов и соответствующих для них типов магазинов:

1) цены выше средней - магазин премиум-сегмента;

2) средняя цена - стандартный интернет-магазин;

3) цена ниже средней - демпингуемый рынок.

На основе этого можно проанализировать наши действия относительно конкурентов и понять, сколько мы выигрываем или проигрываем в ценовой политике. Если у нас цены выше среднего, соответственно наш магазин относится к премиум-сегменту, который будет иметь одну стратегию. Если мы имеем среднюю цену, то можем получить свою аудиторию, пользователей и конверсию без проблем. Однако нужно понимать, что есть площадки, которые могут демпинговать цены, поэтому нам необходимо делать что-то ещё. Но если цена ниже среднего, мы демпингуем рынок и работаем с минимальными ценами, значит, и в топе нам будет хорошо. В различных группах товаров ценовая планка, ценовая политика могут значительно отличаться. Это зависит от того, где мы приобретаем товар и у каких поставщиков. Если у нас на один товар есть уникальные условия с поставщиком или мы являемся официальным представителем, то у нас наименьшая цена по региону, а в случае, когда мы получаем товар от нескольких посредников, приходится им платить наценку и цена у нас будет выше.

Для магазина с низкими ценами SEO будет иметь достаточно хорошую конверсию и показатели трафика. Выйдя в топ, получим отличный трафик с хорошими цифрами и будем получать хорошую прибыль. Работать по классическому продвижению сайта (SEO) здесь будет достаточно выгодно.

Контекстная реклама будет выгодна не всегда. Дело в том, что мы не всегда сможем платить ту цену клика, которую готов платить конкурент. Однако попробовать стоит: на контекстной рекламе идет погоня за теми ключевыми словами, которые будут приносить нам прибыль, хорошую аудиторию за небольшую стоимость клика.

Магазины с низкими ценами имеют высокую виральность (распространенность) в социальных сетях и крауд-маркетинге.

Для магазина с низкими ценами ссылочный профиль (статейное продвижение и тематические ссылки) выступает самым рентабельным вариантом.

Магазин со средней ценовой политикой может применять следующие стратегии:

- классическое SEO позволяет иметь хорошую конверсию;

- контекстная реклама может быть использована выборочно;

- социальные сети и крауд-маркетинг применяются только для наращивания траста сайта;

- ссылочный профиль такой же, как и для магазинов с низкими ценами. Но на сайтах следует обратить внимание на юзабилити (удобство), УТП (уникальность торгового предложения) и КФ (коммерческие факторы).

Коммерческие факторы - это то, на что обращает внимание посетитель сайта, что заставляет его доверять и совершать покупки/заказы на определенных сайтах в результате некой собственной взвешенной оценки. Сюда относятся: цена, ассортимент, наличие контактов, условия доставки, описание компании, свежие новости, реальные отзывы и т. д.

Для магазинов с ценами премиум-сегмента характерны условия:

- классическое SEO имеет более низкую конверсию, но запросы с указанием качества и ценового сегмента здесь будут работать;

- контекстная реклама для данного сегмента достаточно эффективна; 
- в сфере социальных сетей и крауд-маркетига следует выбирать стратегию скрытого маркетинга и работу с лидерами мнений;

- ссылочный профиль в виде контент-маркетинга;

- обязательно следует уделять внимание юзабилити, КФ и УТП.

Интернет-магазинам с сезонными товарами по классическому SEO следует начинать действовать минимум за три месяца до начала сезона продаж. Контекстная реклама в этом случае работает эффективно, но следует учесть данные прошлогоднего сезона с учетом роста спроса. По части социальных сетей и крауд-маркетинга необходимо готовить рекламные компании в рамках SMM на сезон. Ссылочный профиль в форме контент-маркетинга, хоть и дорог, но принесет дополнительных клиентов. Хорошим подспорьем для сезонной интернет-торговли являются медийная реклама с небольшой стоимостью перехода и офлайн-реклама.

Как же учесть в стратегии интернет-магазина ограниченный lifetime товара? В первую очередь следует подготовить посадочные страницы и заняться продвижением за 3-6 месяцев до появления товара. Готовим также PR-стратегию на предварительный заказ в социальных сетях. После снижения актуальности товара либо его удаления ссылки прикрепляем к следующему актуальному товару. Не тратя время на продвижение общих вопросов, уделяем больше внимания картам товаров.

Открыть интернет-магазин не составляет особой сложности, гораздо труднее выбрать верную маркетинговую стратегию для привлечения и удержания клиентов, а также проводить эффективную работу в целях дальнейшего его продвижения [4].

\section{Литература}

1. Интернет-торговля в России 2019: цифры и факты [Электронный ресурс]. Режим доступа: https://www.datainsight.ru/ecommerce 2019 (дата обращения: 12.04.2020).

2. Магомедов А.М., Камилов М.-К.Б. Национальная программа цифровизации и региональные проблемы // Вестник Дагестанского государственного университета. Cер. 3: Общественные науки. - 2019. - Т. 34, вып. 4. - С. 61-71.

3. Максимова-Кулиева Е.A. Цифровизация воспроизводственного обмена и потребление домашних хозяйств // Вестник Алтайской академии экономики и права. 2020. - № 6-2. - C. 271-276.

4. Медведева O.C., Ананьева В.А. Особенности развития интернет-маркетинга в сфере розничной торговли // Инновационная экономика и современный менеджмент. 2019. - № 3. - С. 15-18.

5. Мурар В.И. Современные тенденции развития российского рынка интернетторговли // Вестник Воронежского государственного университета. Сер.: Экономика и управление. - 2019. - № 2. - С. 65-69.

6. Официальный сайт Федеральной службы государственной статистики [Электронный ресурс]. Режим доступа: https://www.gks.ru/folder/11189 (дата обращения: 20.06.2020).

7. Пандемия охватила интернет-торговлю // Коммерсантъ. -2020 - № 110. - С. 7 [Электронный ресурс]. Режим доступа: https://www.kommersant.ru/doc/4390945 (дата обращения: 20.07.2020).

8. Помыткина Л.Ю. Готовность населения к цифровизации экономики // Экономические исследования и разработки. - 2020. - № 2. - С. 13-19.

9. Постановление Правительства РФ от 27.09.2007 № 612 (ред. от 16.05.2020) «Об утверждении Правил продажи товаров дистанционным способом» [Электронный 
pecypc]. Режим доступа: http:// www.consultant.ru/document/cons doc LAW 71418/ (дата обращения: 10.07.2020).

10. Федоров A. Ставка на эксклюзив: как нишевые интернет-магазины отбирают долю у крупных игроков [Электронный ресурс]. Режим доступа: https://www.forbes.ru/biznes/pmef-2018360913 (дата обращения: 10.04.2020).

11. Шайдуллина В.К. Состояние и перспективы электронной торговли в России // Вестник государственного университета управления. - 2019. - № 4. - С. 118-123.

\section{References}

1. Internet-torgovlya $\mathrm{v}$ Rossii 2019: Cifry i fakty. [Elektronnyj re-surs]. URL: https://www.datainsight.ru/ecommerce_2019 (data obrashcheniya: 12.04.2020).

2. Magomedov A.M., Kamilov M.-K.B. Nacional'naya programma cifroviza-cii i regional'nye problemy // Vestnik Dagestanskogo gosudarstvennogo universiteta. Ser. 3: Obshchestvennye nauki. 2019. T. 34. № 4. P. 61-71.

3. Maksimova-Kulieva E.A. Cifrovizaciya vosproizvodstvennogo obmena i potreblenie domashnih hozyajstv // Vestnik Altajskoj akademii ekono-miki i prava. 2020. № 6-2. P. 271-276.

4. Medvedeva O.S., Anan'eva V.A. Osobennosti razvitiya internet-marketinga v sfere roznichnoj torgovli // Innovacionnaya ekonomika i sovremennyj menedzhment. 2019. № 3. P. 15-18.

5. Murar V.I. Sovremennye tendencii razvitiya rossijskogo rynka inter-net-torgovli // Vestnik Voronezhskogo gosudarstvennogo universiteta. Seriya: Ekonomika i upravlenie. 2019. № 2. P. 65-69.

6. Oficial'nyj sajt Federal'noj sluzhby gosudarstvennoj statistiki [Elektronnyj resurs]. URL: https://www.gks.ru/folder/11189 (data obra-shcheniya: 20.06.2020).

7. Pandemiya ohvatila internet-torgovlyu // Gazeta "Kommersant" № 110 of 25.06.2020, p. 7. [Electronic resource]. URL: https://www.kommersant.ru/doc/4390945 (data obrashcheniya: 20.07.2020).

8. Pomytkina L.YU. Gotovnost' naseleniya k cifrovizacii ekonomiki // Ekonomicheskie issledovaniya i razrabotki. 2020. № 2. P. 13-19.

9. Postanovlenie Pravitel'stva RF ot 27.09.2007 № 612 (red. ot 16.05.2020) «Ob utverzhdenii Pravil prodazhi tovarov distancionnym sposobom» [Electronic resource]. URL http:// www.consultant.ru/document/cons_doc_LAW_71418 / (data obrashcheniya: 10.07.2020).

10. Stavka na eksklyuziv: kak nishevye internet-magaziny otbirayut dolyu u krupnyh igrokov (Aleksej Fedorov). [Elektronnyj resurs]. URL: https://www.forbes.ru/biznes/pmef2018360913 (data obrashcheniya: 10.04.2020).

11. Shajdullina V.K. Sostoyanie i perspektivy elektronnoj torgovli v Rossii // Vestnik universiteta. 2019. № 4. P. 118-123.

Поступила в редакичию 23 апреля 2020 г. 
UDC 339.1380

DOI: $10.21779 / 2500-1930-2020-35-2-24-33$

\section{Problems of Distance Commercial Development Under the Pandemic}

\section{A.M. Magomedov}

Dagestan State University; Russia, 367000, Makhachkala, M. Gadzhiev st., 43a; ali1955@mail.ru

The pandemic has made significant adjustments to the structure and content of distance selling. During the quarantine, shoppers quickly adapted to online shopping and a new stable buying habit was formed - buying goods on the Internet. This customer experience should be the fifth «P» of the marketing mix in perspective. Strategic miscalculations in the promotion of online stores lead to the fact that many of the online stores are closed without earning a single ruble. The article offers strategies for the phased promotion of an online store.

Keywords: distance selling, pandemic, online sale, online store, website promotion, marketing strategies.

Received 23 April, 2020 